filling, it will be necessary to replace the stopper, close the air vent, open the stop-cock $D$ and exhaust before proceeding with the distillation.

Fig. 2 is a modification of Fig. I fitted with a Walter's dropping device. The use of the side tube $M$ with its stop-cock, is recommended when it is desirable either to replace air in the apparatus with some other gas, or when it is undesirable to discontinue the distillation in vacuum after refilling the funnel. In the latter case after filling, the funnel and upper part of $\mathrm{C}$ are exhausted by attaching a pump to $M$ while $D, I$ and $H$ remain closed; then $\mathrm{M}$ is closed, $\mathrm{D}$ opened and the conditions are the same as before the flow was interrupted.

A cheaper form of the same apparatus, represented in Fig. 3, gives good results in cases where the reagents used do not attack rubber. This apparatus differs from that in Fig. I, in that the tubes $\mathrm{A}$ and $\mathrm{B}$ are joined by means of a rubber stopper instead of being sealed, and the tube $\mathrm{C}$ is broken at $\mathrm{D}$ and the stop-cock replaced by rubber tubing and a Hofmann's clamp. The length of the tube $A$ is just sufficient to allow its passage through a stopper, thus minimizing the condensation of vapors in $\mathrm{A}$, and the distance that the tube is inserted in the reaction flask is changed by sliding the tube $B$ through the stopper $E$ and adjusting the length of the rubber tube at $D$. This modification of the delivery tube may be made from a common dropping funnel by any one of ordinary ability at glass-blowing, and is especially adapted to use by students, as the flexibility given by the rubber stopper at $\mathrm{E}$ and by the rubber tube at $\mathrm{D}$, reduces the probability of breakage in unskilful hands.

THF UNIVERSTY OF ILLINOIS,

URBANA, ILLINOIS, October 23, 1905.

\title{
SOME OBSERVATIONS ON THE PREPARATION OF METALLIC CALCIUM BY ELECTROLYSIS.
}

BY S. A. TUCKER AND J. B. WHITNEY. Received October $30,1905$.

THE method for the preparation of this metal used was that devised by J. H. Goodwin, ${ }^{1}$ and the attempt was made to improve the yield of the metal if possible.

The apparatus used was similar to that employed by Goodwin,

1 Proc. Am. Phil. Soc. (Phil.) 43, $38 \mathrm{r}$. 
and consisted of a graphite crucible turned from an Acheson graphite electrode. This crucible constituted the anode and the

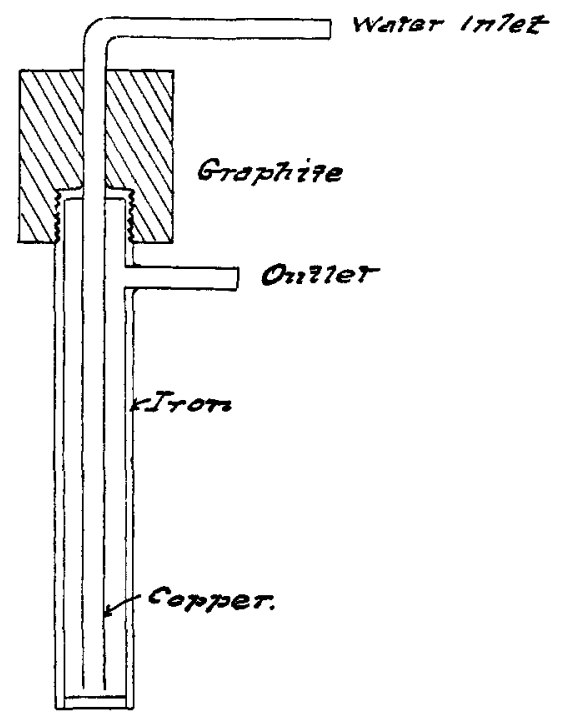

water cooted Etectroce

cavity for the electrolyte was $10 \mathrm{~cm}$. in diameter by $10 \mathrm{~cm}$. deep. The bottom was water-cooled by a coil of copper tube, through which water was circulated, let into the bottom of the crucible. This water-cooling conducts off heat through the thin bottom of graphite, which is made about $3 \mathrm{~mm}$. thick.

A layer of fluorspar is placed upon this, and thus the bottom is protected by a solid crust of the electrolyte during the actual process. At first an iron rod $15 \mathrm{~mm}$. in diameter was used as kathode, as it was desired to test the running of the process on the lines indicated by Goodwin. This kathode was adjustable by means of a wheel and screw mechanism so that it could be elevated or depressed at will.

The raw material for the electrolyte was commercial fused calcium chloride. This is first fused down under the blast-lamp in another crucible, and great care is necessary to insure the absence of any water before introducing it into the anode chamber.

When thoroughly free of water it is poured upon a layer of fluorspar placed on the bottom of this crucible, until the latter 
is nearly full. The kathode is immediately lowered and the current turned on.

The heating effect of the current readily melts any of the calcium chloride which may have solidified during the pouring.

When the chloride becomes fluid, calcium immediately begins to collect around the iron kathode, and this is gradually withdrawn in order to get the metal away from the heating influences of the bath as soon as possible, otherwise it is rapidly oxidized.

A number of experiments were made in this way and it was found that with the size of the apparatus given it was only possible to work satisfactorily when the current was kept between the limits of 125 and I50 amperes. With the heavier current the bath became too hot in most cases with consequent loss of calcium by oxidation; if on the other hand the current is allowed to fall to 25 amperes, the metal is deposited in a spongy condition.

It is therefore highly essential that the temperature of the bath be kept constant, and this point should be just below that at which oxidation of the metal begins to take place. Determination of this point by pyrometer measurements gave $720^{\circ} \mathrm{C}$. It seemed therefore if the temperature of the kathode could be kept at about $7 \mathrm{I} 5^{\circ} \mathrm{C}$, a better yield of the metal would restrlt.

Regulation by current alone to such fine limits is difficult, and a water-cooled kathode was therefore tried which was found to be successful. The water-cooling was effected by the arrangement here shown, and consists of a piece of gas pipe plugged at one end, and having the water intake near the bottom by means of the bent tube. Another tube takes off the water at the top. The plugging at the bottom should be as thin as possible, as the object is to get the maximum cooling effect to the calcium as it is formed. In this way the metal is cooled almost as it is formed with the result that the yield is much increased. Working with this water-cooled kathode it was found that a yield of 60 per cent. could be obtained.

It is, however, necessary to remove the calcium as it is formed from actual contact with the electrolyte, and this is accomplished by raising the kathode gradually by the hand-wheel; when the rod of calcium thus formed becomes so long that the cooling effect of the water circulation is lost, the metal is removed and 
the process again resumed by bringing the cooled iron in contact with the electrolyte.

It is necessary to make this change fairly rapidly, as the temperature of the bath must not be allowed to fall much from that at which the electrolysis takes place. From time to time molten calcium chloride is added to the bath and the process may, in this way, be carried on for a considerable length of time.

Under any circumstances it was found that there was a very considerable loss of the metal due either to oxidation or to recombination of it with the chlorine from the anode. Some experiments were therefore tried with a view to preventing this loss. The kathode was so constructed that the iron rod was surrounded with a graphite bell, the rod being insulated by mica bushings from contact with the graphite. The space inclosed by the bell was about $50 \mathrm{cc}$. and it was thought probable that the calcium would collect in this space out of contact with the air and away from the influence of the chlorine from the anode. It was found, however, that this arrangement did not give good results, probably from the fact that graphite was used as a material for the bell, as short-circuiting took place soon after it was put in operation. As soon as the bell becomes a conductor it merely acts as a large kathode, decreasing the current density at this point to such a degree that good results are impossible.

COLUMBIA UNTVERSITY.

\section{POTASSIUM MERCURIC FERROCYANIDE.}

By Gustave Fernekes.

Received November 10, 1905 .

ON ADDING a solution of potassium ferrocyanide to a solution of mercuric chloride, a yellowish precipitate is at first obtained, which, on standing, turns blue. A qualitative examination of this blue precipitate led me to consider it as potassium mercuric ferrocyanide. On looking into the literature I found no mention of a compound such as I supposed that I had obtained. Kane ${ }^{1}$ obtained a compound $\mathrm{K}_{4} \mathrm{Fe}(\mathrm{CN})_{6}+{ }_{3} \mathrm{Hg}(\mathrm{CN})_{2}$ $+{ }_{4} \mathrm{H}_{2} \mathrm{O}$ by acting upon a hot solution of mercuric cyanide with potassium ferrocyanide. Loewe ${ }^{2}$ obtained the same compound by shaking a moderately concentrated solution of potassium

${ }^{1}$ J. pr. Chem. 19, 405.

${ }^{2}$ Jsb. Chem. I857, p. 273. 